
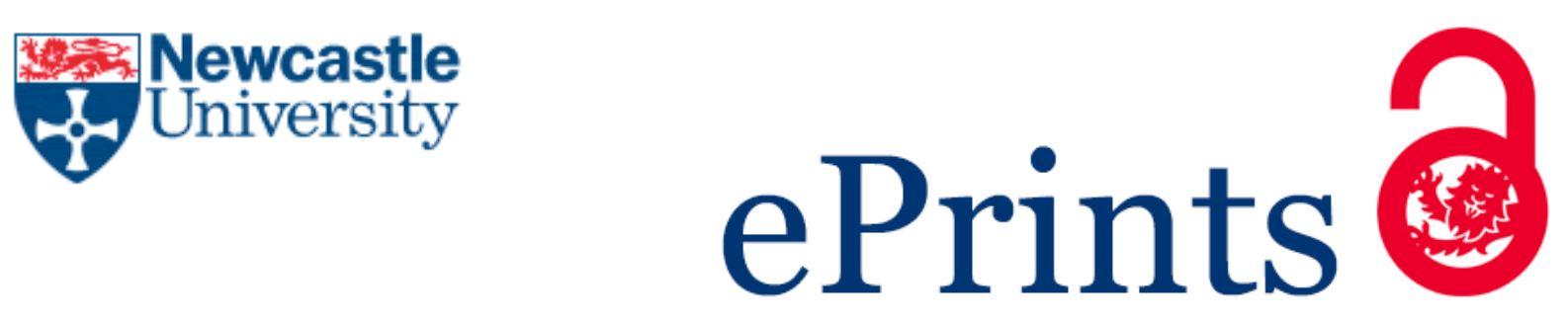

\author{
Jones M, Blenkinsop S, Fowler HJ, Kilsby CG. \\ Objective classification of extreme rainfall regions for the UK and updated \\ estimates of trends in regional extreme rainfall. \\ International Journal of Climatology 2014, 34(3), 751-765.
}

\title{
Copyright:
}

This is the peer reviewed version of the following article: Jones M, Blenkinsop S, Fowler HJ, Kilsby CG. Objective classification of extreme rainfall regions for the UK and updated estimates of trends in regional extreme rainfall. International Journal of Climatology 2014, 34(3), 751-765, which has been published in final form at http://dx.doi.org/10.1002/joc.372 This article may be used for noncommercial purposes in accordance with Wiley Terms and Conditions for Self-Archiving.

DOI link to article:

http://dx.doi.org/10.1002/joc.3720

Date deposited:

$19 / 08 / 2016$ 


\section{Objective classification of extreme rainfall regions for the UK and updated estimates of trends in regional extreme rainfall}

\begin{tabular}{|r|l|}
\hline Journal: & International Journal of Climatology \\
\hline Manuscript ID: & Draft \\
\hline Diley - Manuscript type: & Research Article \\
\hline Complete List of Authors: & $\begin{array}{l}\text { Jones, Mari; National Center for Atmospheric Research, MMM; Newcastle } \\
\text { University, School of Civil Engineering and Geosciences } \\
\text { Blenkinsop, Stephen; Newcastle University, School of Civil Engineering and } \\
\text { Geosciences } \\
\text { Fowler, Hayley; Newcastle University, School of Civil Engineering and } \\
\text { Geosciences } \\
\text { Kilsby, Chris; Newcastle University, School of Civil Engineering and } \\
\text { Geosciences }\end{array}$ \\
\hline Keywords: & $\begin{array}{l}\text { Extreme rainfall, UK and Northern Ireland, Principal Component Analysis, } \\
\text { Spatial Patterns }\end{array}$ \\
\hline & \\
\hline
\end{tabular}


Objective classification of extreme rainfall regions for the UK and updated estimates of trends in regional extreme rainfall

Mari R. Jones $^{1,2}$, Stephen Blenkinsop ${ }^{2}$, Hayley J. Fowler ${ }^{2}$, Christopher G. Kilsby ${ }^{2}$

${ }^{1}$ National Center for Atmospheric Research, P.O. Box 3000, Boulder, CO, 80307

${ }^{2}$ School of Civil Engineering and Geosciences, Newcastle University, Newcastle-upon-Tyne, NE1 7RU, UK

Key words: Extreme rainfall; UK and Northern Ireland; Principal components analysis; Spatial patterns; precipitation

\section{Abstract}

Regional frequency analysis of pooled extreme rainfall to estimate the likely impacts of a changing climate is a well established method. However, previous analyses of country-wide changes to UK extreme daily rainfall have used the 9 Hadley UK Precipitation (HadUKP) regions (Alexander and Jones, 2000). While these characterise well the mean daily intensity and frequency of rainfall within each region, extreme rainfall climatology differs from that of the mean characteristics. As a result the existing HadUKP regions do not represent extreme rainfall behaviour adequately, with regard to the frequency, intensity or timing of extreme rainfall events.

Focussing on many extreme rainfall characteristics, such as the seasonal timing and magnitude of maxima, this article presents a formal representation of extreme rainfall regions which specifically describe extreme spatial and temporal characteristics. The article concludes with a brief exploration of improved estimates of extreme daily rainfall event estimation using these extreme rainfall regions. The new regional definitions provide clearer upward trends in annual maxima over the period 1961-2010 than those estimated using the HadUKP regional pools. 


\section{Introduction}

Climatic extremes such as floods arising from extreme rainfall events pose multi-dimensional hazards to critical infrastructure and the most vulnerable sectors of society and are expected to become more frequent with global warming (IPCC, 2011). Yet, by definition, these extreme rainfall events are rare and have a commensurate lack of data with which to estimate their probable annual return frequency for the purposes of design and risk management in the current climate, or under projected future climate conditions.

Extreme value analysis to estimate the likely magnitude of extreme rainfall events with a specific probability is a well-recognised technique, with practical applications in engineering design, policy making or water resource management (e.g. Fowler and Kilsby, 2003a,b; Villarini et al., 2011). However, this approach is hampered by a need for adequate data - approximately five times that of the event return frequency; that is, 500 years of data for an event with $1 \%$ annual probability (Faulkner, 1999). Regional frequency analysis (RFA) makes use of regionally pooled extreme rainfall observations to estimate quantiles for any site within a specific region (Cunnane, 1988); this is particularly beneficial at locations which have limited duration records. In the UK extensive river discharge records are available to create pooling groups of similar river catchments and so estimate flood flows; however, similar records of rainfall are less readily available. As a result, previous analyses of the likely changes to UK-wide extreme rainfall have made use of the nine Hadley UK Precipitation (HadUKP) regions (Alexander and Jones, 2000).

The HadUKP regions, developed from the England and Wales precipitation regions (Wigley et al., 1984), were used to generate regional daily rainfall series (Alexander and Jones, 2000) which replicate well the characteristics of intensity and frequency of regional mean daily rainfall. These regions are also well established as a comparative tool, having been used to examine changes in current and projected extreme rainfall (e.g. Jones and Conway, 1997; Fowler and Kilsby, 2003a; Fowler and Ekström, 2009; Fowler and Wilby, 2010; Jones et al., 2012), and were found to be non-discordant for daily rainfall extremes by Fowler and Kilsby (2003a). However, the HadUKP regions are spatially diverse and are not fully representative of the sub-regional variations in extreme rainfall frequency, magnitude and seasonality which are present due to orographic differences within each region. The processes responsible for extreme rainfall differ from those which generate the mean climatology; therefore, regions which are defined from mean rainfall characteristics will not reflect the spatial characteristics of extreme rainfall climatology. As a result, some regions such as North West England and South West England combine several areas with very different extreme rainfall 
responses, which limits their applicability for assessments of likely changes in extreme rainfall. Furthermore, the original England and Wales precipitation regions (Wigley et al., 1984) used a principal component analysis of the mean rainfall characteristics (1861-1970) from only 55 observation stations, of which only 25 were located in England and Wales.

Figure 1 illustrates the differences between the extreme rainfall responses for each station in the North West England HadUKP region; Figure 1(a) depicts the frequency density of extreme event occurrence per day of the year, effectively the seasonality at each station, while Figure 1(b) illustrates the range of annual maxima over the period 1961-2010 for each station. Figure 1(a) highlights that in addition to known regional differences in the timing and duration of mean wet days (days with rainfall $\geq 1 \mathrm{~mm}$ ), there are also considerable differences in the timing of rainfall maxima and the duration of the period over which these occur in response to the different governing weather systems across the spatial domain (e.g. North Atlantic fronts, or summertime convection). Pooling such a diverse mix of rainfall maxima may affect any statistical analyses by combining several sources of variability. Similarly, although the differences in event magnitude arising from orographic enhancement can be minimised by standardising station maxima prior to regional pooling, when the overall distribution of the annual maxima are different this can lead to non-homogeneous RFA estimates. The "growth curves" developed from station annual maxima in Figure 1(b) are highly variable, representing considerable differences between station distributions, with some stations having a steep growth curve and others much flatter curves; the differences again reflect responses to different dominating weather systems.

Figure 1 : Comparison of timing and magnitude of extreme rainfall at each station in the HadUKP North West England region

We consider that the use of regions defined from mean annual characteristics may not be appropriate for use in a study of extreme rainfall; however, alternative regional definitions based on water company jurisdictions (Blenkinsop and Fowler, 2007), or governance regions, such as those used within the UK Climate Projections (Murphy et al., 2009), do not necessarily relate directly to climatic responses. More detailed regional rainfall classifications have been developed for several different applications (Bonell and Sumner, 1992; Hossell et al., 2003; Neal and Phillips, 2009), using a principal component analysis of daily rainfall. Gregory (1975) examined different regions of rainfall behaviour throughout England, Wales and Scotland on the basis of fluctuations in total annual rainfall volumes. However, as with the HadUKP regions, these were all developed from mean daily rainfall characteristics and so do not fully reflect the different behaviour of extreme rainfall within each sub-division (Macdonald et al., 2010). Hydrological designs in the UK have also $\sim 3 \sim$ 
made use of the regional flood frequency growth curves provided in the Flood Studies Report (Institute of Hydrology, 1975) to facilitate regional estimates of extreme rainfall. The ten regions cover wide ranges of topography and meteorological responses and were developed from stream flow annual maxima and so are less representative of extreme rainfall characteristics.

Approaches used by others to identify 'regions' (Alexander et al., 2006; Coelho et al., 2008) have examined all extremes on an individual point basis before applying spatial clustering at a later stage to identify geographical regions which display similar behaviour, or by visually grouping proximate stations with similar behaviour (Maraun et al., 2008). Others have applied a spatial component in Bayesian extreme value analyses of rainfall (Cooley et al., 2007; Ribatet et al., 2007), necessitating individual station analyses and a wealth of data which may not be readily available for all analysts. A final tool, used to effect by many (e.g. Wigley et al., 1984; Dales and Reed, 1989; Neal and Phillips, 2009) for later pooled statistical analyses, is to identify linear patterns within the rainfall characteristics using Principal Component Analysis (PCA) followed by a clustering analysis to identify regional groups (Blenkinsop et al., 2008). Thus, specifically defined extreme regions would be beneficial to enable extreme rainfall observation pooling, and so enhance estimates of event frequency and magnitude for all impact assessments.

Hosking and Wallis (1988) discussed methods to pool groups of similar catchments affected by the same widespread extreme rainfall events, which can then be studied in relation to external drivers or weather types (Lamb, 1972); they used this to improve extant regional frequency analysis methods but did not specifically identify extreme rainfall regions. Introducing their definition of 12 homogenous regions, premised on extreme rainfall characteristics, Dales and Reed (1989) also summarised previous alternatives for regional rainfall.

The extreme regions derived by Dales and Reed (1989) were devised from a subjective clustering of stations according to GEV distribution characteristics, RBAR (mean of annual maxima from the Flood Studies Report, 1975) and coefficient of variance. Their initial selection of regions, taken from Jackson and Larke (1974), was subdivided throughout England to reflect real differences in extreme rainfall patterns. However, the authors acknowledged that the Wales, Scotland and Northern Ireland regions require further delineation and that all regions would benefit from refinement using additional rainfall observations. This article describes the process to create extreme daily rainfall regions from measures of extreme rainfall intensity, frequency, climatological behaviour and seasonality. By using considerably more gauged observations and variables, specifically directed 
at extreme daily rainfall characteristics, both the spatial coverage of the regions and their applicability to analyses of the extremes are considerably enhanced.

The data and methods used to develop the UK extreme rainfall regions are described in Section 2; the variables selected to describe extreme rainfall behaviour and the development of the extreme rainfall regions is outline in Section 3. Regional frequency analyses of daily rainfall annual maxima (AMAX) are presented in Section 4, while Section 5 discusses the results and conclusions.

\section{Data and Methodology}

\subsection{Data}

Daily rainfall observations with a wide spatial extent across the UK were used for the development of the extreme regions (Jones et al., 2012). The data set comprises 223 stations, each with a minimum record duration of 40 years, spanning the period 1856-2010 with a latest start date of $1961 ; 19$ stations cover only the period 1961-2000. While 24 station records contained too many consecutive missing years of observations for use in peak over threshold (POT) analyses, crossverification of station maxima using sources such as British Rainfall enabled the use of all 223 stations for analyses based on annual maxima (AMAX). Tests to verify each station maxima series, and the processes to achieve reliable homogeneous data, are summarised in Jones et al. (2010); station details including regional allocations are included in supplementary material and Figure 5.

POT rainfall maxima were identified from each station observation series using a station specific threshold for extremely wet days (Q99; Alexander et al., 2006), that is the 0.99 quantile of the wet day distribution. Each extreme rainfall event was separated by an interval of at least 2 days, determined from the declustering index (Ferro and Segers, 2003), to ensure that only independent events were considered in the analysis.

\subsection{Principal Component Analysis}

A widely used technique for reducing large multivariate statistical data to a smaller, equally descriptive, data set is that of Principal Component Analysis (PCA; Wilks, 2005). The principal components are formed from linear combinations of the original data where each combination has been selected to describe the maximum proportion of the original data variability through correlations between the variables. Including too many similar variables in the analysis set can introduce apparent correlations and minimise the efficacy of the PCA, thus there is a balance to be achieved in the selection of input parameters without introducing bias.

$$
\sim 5 \sim
$$


An effective way to identify patterns within the principal component scores, and so group similarly behaving stations, is to cluster the stations according to location and score. The three main clustering approaches which can be applied are: hierarchical, whereby groups of similarly behaving components are gradually aggregated in a cluster tree; model based approaches, where the Bayes criteria are used to identify the most likely model and number of clusters; or partitioning, where the data are grouped according to their weighted distance and score differential from the mean of a group centred around a chosen point (Wilks, 2005). We have selected the $k$-means partition cluster analysis (Hartigan and Wong, 1979) applied to the scores of selected principal components as the most appropriate technique to identify coherent groupings of the components and, thus, the stations within each region. A drawback of $k$-means clustering is that the optimum number of clusters must be defined by the analyst, which can be problematic if the value is not known a priori (Wilks, 2005); this is easily rectified by sensitivity testing of several potential cluster group sizes.

\subsection{Distributions for parameter selection}

Following the method used by Dales and Reed (1989), extreme value theory was applied to the AMAX and POT maxima in order to use distribution parameter estimates as variables in the PCA. The AMAX follow a Generalized Extreme Value (GEV) distribution:

$$
G(x ; \mu ; \sigma ; \xi)=\exp \left[-\left(1+\frac{\xi(x-\mu)}{\sigma}\right)^{-1 / \xi}\right] \quad \text { where } 1+\frac{\xi(x-\mu)}{\sigma}>0
$$

with parameters, location $-\infty<\mu<\infty$, scale $\sigma>0$ and shape $-\infty<\xi<\infty$; while the POT maxima follow a Generalized Pareto Distribution:

$$
H(y)=1-\left(1+\frac{\xi y}{\tilde{\sigma}}\right)^{-1 / \xi}
$$

with parameters shape, $\xi$, and scale, $\tilde{\sigma}$. The two distributions are directly related through the shape parameter. A more detailed explanation of these distributions can be found in Coles (2001). Parameter estimates for both distributions were obtained from L-moment relationships (Hosking, 1990) to facilitate regional frequency analyses of pooled maxima at a later stage. Assuming the location parameter is known, the remaining distribution parameters were estimated from the following GEV and GPD relationships,

GPD:

$$
\begin{aligned}
& \xi=2-\frac{\lambda_{1}-\hat{u}}{\lambda_{2}} \\
& \tilde{\sigma}=(1-\xi)\left(\lambda_{1}-\hat{u}\right)
\end{aligned}
$$

$$
\sim 6 \sim
$$




$$
\begin{aligned}
& c=\frac{2}{3+\tau_{3}}-\frac{\ln 2}{\ln 3} \\
& \xi=7.8590 c+2.9554 c^{2} \\
& \mu=\lambda_{1}-\frac{\sigma[1-\Gamma(1+\xi)]}{\xi} \\
& \sigma=\frac{\lambda_{2} \xi}{\left(1-2^{-\xi}\right) \Gamma(1+\xi)}
\end{aligned}
$$$$
\text { GEV: }
$$

(4)where

$\hat{u}$ is the location parameter, or threshold, and $\lambda_{1}$ and $\lambda_{2}$ are the first and second L-moments of the series maxima and $\Gamma$ is the Gamma function.

Rotated seasonal statistics (Robson, 1999) were adopted to identify seasonality characteristics. Converting the angular position of the calendar day (at noon), $\theta$, in radians, to a vector based quantity of mean direction, $\bar{r}$, and centroid of action, $\bar{\theta}$, for $M$ events at $i$ stations gives an estimate of the seasonal concentration of all events. $\bar{r} \rightarrow 1$ indicates a regular seasonal concentration of events and $\bar{r} \rightarrow 0$ indicates weak seasonality.

$$
\begin{gathered}
\bar{x}=\frac{1}{n} \sum_{i=1}^{M} \cos \theta_{i} \quad \bar{y}=\frac{1}{n} \sum_{i=1}^{M} \sin \theta_{i} \\
\bar{r}=\sqrt{\bar{x}^{2}+\bar{y}^{2}} \\
\bar{\theta}=\left\{\begin{array}{ccc}
\tan ^{-1}\left(\frac{\bar{y}}{\bar{x}}\right) & \bar{x} \geq 0 \quad \bar{y} \geq 0 \\
\tan ^{-1}\left(\frac{\bar{y}}{\bar{x}}\right)+\pi & \bar{x}<0 \\
\tan ^{-1}\left(\frac{\bar{y}}{\bar{x}}\right)+2 \pi & \bar{x} \geq 0 \quad \bar{y}<0
\end{array}\right.
\end{gathered}
$$

The extreme regions, once developed, will be used to assess changes in the magnitude of extreme daily rainfall events using RFA (Hosking and Wallis, 1997). RFA makes use of extreme value distributions fitted to pooled regional maxima to estimate the magnitude of events with a set target annual probability (e.g 1\% or 1 in 100 year return frequency). Regional pools are established from time series of individual gauge maxima within each region by standardising each station by the individual station median annual maximum value (RMED) to remove orographic or exposure effects prior to pooling. Regional RMED values are calculated from the weighted mean of all gauges in the region, where individual station weighting is based on the effective record length to reflect the reliability of the relevant set of observations (Hosking and Wallis, 1988): 


$$
w_{i}=\frac{n_{i}}{\sum_{i=1}^{N} n_{i}}
$$

where $w_{i}$ is the effective record length at the $i$ th station, $N$ the number of stations in the pooling group and $n$ represents the number of station years. The appropriate distribution is then fitted to the standardised maxima using regionally weighted L-moments.

\section{Extreme Rainfall Regions}

\subsection{Variable selection}

A set of extreme rainfall parameters was investigated to identify the most descriptive variables which account for climatological influences and topographical differences, and so to assign regional divisions (Wigley et al., 1984; Dales and Reed, 1989; Phillips and McGregor, 2002; Hossell et al., 2003). The variables described below were selected to capture the differences in event magnitude, range in individual station maxima and frequency of events which arise from regional differences in elevation and dominating weather systems.

Others have shown that the frequency of UK extreme daily rainfall follows a seasonal pattern, which differs from that of mean wet days, and is distributed non-uniformly towards the latter half of the year (Rodda et al., 2009; Jones et al., submitted) with very few extremes occurring during mid to late spring. Furthermore, extremely heavy rainfall events (above the 0.99 quantile of the wet day distribution) do not occur uniformly throughout the year and, as illustrated in Figure 1, there are considerable regional variations in the timing of the peaks arising from the dominating weather systems. For instance, stations located in the northwest of the UK tend to be dominated by North Atlantic winter frontal systems, with the largest daily maxima likely to occur over the late autumn and winter months. In contrast, the southeast of England tends to be dominated by short duration summer convective events, exacerbated by temperature differentials between land and ocean. Typical event frequency density plots for these regions would have a single peak in either the summer or autumn; while the combination of both influences gives rise to a bi-modal seasonal response in other parts of the UK (Jones et al., submitted). As these spatial differences in timing are considered to be a key descriptor of regional extreme rainfall behaviour, seasonality was included as a variable in the spatial analysis.

As illustrated by Figure $1 \mathrm{~b}$, there are considerable spatial differences in the magnitude and range of rainfall maxima received at each station. While differences in magnitude may reflect orographic enhancement, the range in the magnitudes indicate the heaviness of the tail arising $\sim 8 \sim$ 
from different governing weather systems. Stations in the northwest of the UK are known to exhibit heavier tailed distributions due to the influence of large rain-bearing systems from the North Atlantic (e.g. Fowler and Kilsby, 2003a). Parameters such as the median annual maximum value (RMED) per station were key to deriving regional relationships between individual station observations. Similarly, fitted extreme value distributions were also beneficial, by enhancing the depiction of the rainfall maxima tail-behaviour through the distribution location, scale and shape parameters. Analyses of extreme value distributions can assist with describing differences in the data and have been shown to represent spatial variability very well (Fowler et al., 2010). Excesses over the $99 \%$ wet day quantile (Q99) were adopted in preference to AMAX to maximise the data used in the analyses, and a Generalized Pareto Distribution was fitted at each station.

The final selection of variables used in a principal component analysis (PCA) to classify regions with coherent behaviour was subjective, identifying a range of measures which represented different types of responses to typical oceanic and atmospheric systems. The variables are summarised in Table 1.

Table 1 : Rainfall variables used in Principal Component Analysis for Extreme Regions

Maps of RMED, thetabar, rbar $_{\text {se }}, \mathrm{R} 20$ sum, RWIN and sigmatilde estimates are depicted in Figure 2. Ksi is not depicted as it presented little regional coherence, possibly due to the difficulties in estimating this parameter with any accuracy (Katz, 2010). However, the shape parameter controls the weight of the tail of the distribution of maxima (Fowler et al., 2010) and gives an indication of regional tendencies, e.g. the range of maxima is much higher in northern mountainous regions than in the south east; for this reason it was retained in the analyses. The seasonality measures (Figure 2, b to e) highlight the tendency for higher altitude regions to receive their maximum rainfall during the winter, and lower lying locations in the summer, while the Midlands have far less distinctive seasonality. A similar regional structure is reflected in the station value of RMED (Figure 2a), where higher stations (coincidentally closer to the North Atlantic Ocean) receive the largest rainfall totals; while stations in the south and east tend to have a far greater range in the magnitude of recorded maxima (Figure $2 \mathrm{f}$ ), reflecting the dominance of summer convective storms in these locations.

Figure 2 : Some measures of extreme rainfall used in a principal component analysis calculated for 1961-1990 period (a) RMED; (b) Rotational measure of day of event (c) Coherence of seasonality; (d) Count of summer days $>20 \mathrm{~mm}$; (e) Mean winter wet day value; (f) Fitted GPD scale parameter.

\subsection{Principal Component Analysis}

Several combinations of the measures in Table 1 were assessed with PCA, using a minimum of four parameters, to minimise redundant repetition of variables (Jolliffe, 1973); eventually using all $\sim 9 \sim$ 
tabulated parameters to derive the components and assess the most coherent grouping of the stations. Identifying the most appropriate number of principal components is largely subjective, based on scree plots (Figure 3) or a rule-of-thumb approach such as selection of components with eigenvalues $>1$ (Kaiser, 1960), eigenvalues $>0.7$ (Jolliffe, 1972), or the number of components required to explain a target percentage of the data variance. All tests were examined and these suggested use of either the first three or four components to classify stations.

Figure 3 : Scree plot of principal components

The first three components explain $72.6 \%$ of the data variance, increasing to $80.1 \%$ with the fourth component; while the first three eigenvalues all exceed 1 , the fourth is 0.88 . Table 2 indicates the loadings of each variable for each of the first four components, with the two absolute largest values highlighted in bold. Some caution must be applied in interpreting the behaviour represented by each principal component as the centre of action may not be accurate (Dommenget and Latif, 2002). However, the first component (PC1) appears to relate to the magnitude of the maxima, and the relative regional wetness or response to atmospheric circulation patterns. PC2 seems to reflect the differences in extreme event magnitude, such as skew and variability; PC3 seems to describe the seasonality of events. PC4 appears to describe the response to location, topography and station aspect or exposure; as this component is somewhat ambiguous, and explains much less of the data variance, it was not retained in the analysis. The smoothed scores for the first three principal components are shown in Figure 4 and highlight the responses to orography (Figure 4a) with the higher mountain chains highlighted in reds; the larger range of extreme event magnitudes in the east of England is clear, and in this way is suggestive of the seasonal pattern in event occurrence (Figure 4b). Tendencies towards a single peak in seasonal event frequency are apparent in northwest Scotland and southeast England where one dominating weather system dominates the timing of rainfall maxima; while other parts of the UK may be influenced by a combination of weather types and exhibit bi-modal seasonality (Figure 4c).

\subsection{Classifying regions}

K-means cluster analysis (Hartigan and Wong, 1979) was applied to the scores of the retained components for each station, relative to the station latitude and longitude; sensitivity testing confirmed that the first three principal components produced the most comprehensive regional partitioning with fewest randomly displaced members from the main groups. Clusters were examined for target group numbers between $11<k<20$, as the minimum requirements of the regional definition were to reduce the spatial extent of larger heterogeneous HadUKP regions and

$$
\sim 10 \sim
$$


to improve the boundary definitions to reflect the extreme behaviour, whilst avoiding excessive sub-division.

Table 2 : Loadings of each variable within the first four principal components and proportional contribution (in italic) to the variance. Bold type indicates most significant contributing variables.

Cluster analysis applies a random partitioning of the selected data, in this case the station principal component scores, centred on the initial latitude and longitude seed positions at approximately the centre of each regional cluster. Algorithms iterate to a solution with the smallest distance between the cluster centroid and the group members. An advantage of clustering by $k$ means groups over hierarchical methods is that cluster members can be reallocated to more relevant clusters throughout the process. In common with other climatic clustering analyses, it was found that above a critical level increasing the number of clusters fragmented the smaller regions rather than arriving at a more comprehensive partitioning of all stations (Corte-Real et al., 1998; Blenkinsop et al., 2008; Raziei et al., 2011). Examination of the within sum of squares and between sum of squares statistics for each cluster suggested an optimum partitioning of between 13 and 16 clusters; closer examination of these revealed that some of the smaller clusters could be combined, arriving at a solution of 14 UK extreme rainfall regions shown in Figure 5.

Figure 4 : Scores of principal components derived from the variables listed in Table 1 where (a) PC1 describes maxima; (b) PC2 describing variance in maxima; (c) PC3 describing seasonality

\subsection{Regional homogeneity}

Each extreme rainfall region was then tested for homogeneity using: i) the discordancy measure for each station, D (Hosking and Wallis, 1997), ii) the regional homogeneity statistic, $\Theta$ (Hosking and Wallis, 1993) and iii) the Anderson-Darling rank test statistic (Stedinger et al., 1993). The discordancy measure is a reliable estimator of homogeneity only for regions with more than 5 sites (Hosking and Wallis, 1997), and was used in combination with other homogeneity tests to identify potential sources of discordancy within the regional pool.

The Hosking and Wallis regional homogeneity statistic is most reliable where the regional Lmoment estimate of skew, is $<0.23$ (Viglione, 2011); that is where the range of maxima observed at each station in the region is low. Regions were considered to be homogeneous where $\Theta<1$, possibly heterogeneous for $1 \leq \Theta \leq 2$, and definitely heterogeneous if $\Theta>2$ (Hosking and Wallis, 1997). For regions with a high regional skewness measure, such as those with large elevation changes, the Anderson-Darling measure is more appropriate. The Anderson-Darling test statistic (Viglione et al., 2007). is a generalisation of the goodness of fit test, with the significance of the homogeneity score obtained from a bootstrap analysis (Viglione, 2011). The statistic was tested at a 
significance level of $95 \%$, with the null hypothesis of a homogenous region being rejected for all $p$ values $>0.95$.

Most regions contain at least 10 stations with the exception of Mid Wales (MW), which only contains five stations, and Humber (HU) with nine. Five stations are sufficient to calculate regional frequency estimates but these will also incorporate high uncertainty estimates (Hosking and Wallis, 1997; Jones et al., 2010); however, a balance must be achieved between high uncertainty and oversmoothing of the extreme characteristics.

Figure 5 : UK Extreme Rainfall Regions identified from a principal component analysis of extreme rainfall measures. North Highlands and Islands (NHI), East Scotland (ES), South Scotland (SS), Forth (FOR), North Ireland (NI), Solway (SOL), North West (NW), North East (NE), Humber (HUM), Mid Wales (MW),

East Anglia (EA), South West (SW), West Country (WC), South East (SE). HadUKP regions included in inset for reference.

The results of the different homogeneity tests are outlined in Table 3. The discordancy measures for all stations in each of the regions were below the critical values; however, note that stations within the HadUKP regions (Wigley et al., 1984) were also found to be non-discordant by Fowler and Kilsby (2003a) when using the individual Hosking and Wallis (1997) discordancy measures. Some stations had near critical discordancy measures, included in column 4 of Table 3, and were examined for their influence on the regional homogeneity; as the regions were otherwise homogeneous, most regional groupings were not altered.

Table 3 : Extreme rainfall regions tests for homogeneity using the Hosking and Wallis heterogeneity test based on Lmoment coefficient of variance, Anderson-Darling bootstrap test and discordancy measure. Bold font indicates critical test values exceeded, italic font indicates near critical values.

High discordancy scores can often arise from one anomalous rainfall event and so do not provide conclusive evidence of heterogeneity. All regions with high scores were investigated further, considering the most likely source of heterogeneity to be the most discordant site. It should be noted that each anomalous instance of rainfall maxima had previously been verified against other records to ensure full gauged record homogeneity. Given the limits of data availability in more remote locations (e.g. Scottish Highlands or Wales uplands), regions achieving marginal scores and containing some discordant sites were considered to be homogenous where an improvement could not be directly identified.

The North West (NW) region was found to have a very high heterogeneity measure, although an insignificant Anderson-Darling score, caused by the gauge at Worthington Water Works located in the centre of the region. This station was not reallocated, although the score may have been ascribable to several large events, as an improvement to the score could only arise from the creation of a separate interior region, which was not considered appropriate. The North Highlands 
and Islands (NHI) region, which is a highly skewed region, also had a significant heterogeneity measure according to all three tests. Once again, the score can be ascribed to one station which is well within the North Highlands and would not be appropriate in a separate region. Cassley, the anomalous station, recorded several high rainfall totals including $158.2 \mathrm{~mm}$ on 22 October 1971 and $145 \mathrm{~mm}$ on 6 February 1989. A heterogeneous rating was found in the Solway region (SOL), arising from the inclusion of the Isle of Man. In the absence of supporting data, it was decided not to create a specific region for the Isle of Man, but to maintain the current allocation which is supported by the PCA scores for all stations in this cluster.

One station in the Forth (FOR) region was found to have a high discordancy score, located near to the regional border, although the Hosking and Wallis heterogeneity measure indicates possible heterogeneity. The location of this site is such that two adjacent stations of similar characteristics would also need to be reallocated to South Highlands (SH) if the regional border were amended. Although the other two stations did not have high discordancy measures, the revised homogeneity scores were calculated for changed regional boundaries, moving all three stations into $\mathrm{SH}$. The revised allocations marginally improved the homogeneity ratings for both regions and thus have been adopted in the final regional boundary definition.

While it is possible that there are too few gauges in some regions to characterise the differences in behaviour or to be confident that the regions are fully homogenous, the allocation is considered robust and representative of regional extreme rainfall behaviour. Where boundaries were not dictated by station location, such as around Solway, Mid Wales or the South East, they were adopted in common with those used by Dales and Reed (1989) and the UK Climate Change Impacts Programme River Basin Regions (Murphy et al., 2009). The final boundary definition is pragmatic and would benefit from more detailed analysis and refinement with a considerably larger data set, particularly for larger regions such as SH which are delineated by topographic features.

\section{Results}

To test the efficacy of the extreme rainfall regions, a RFA was undertaken to examine the relative magnitude of extreme daily rainfall in each region. As the regions were characterised from POT rainfall 1-day maxima, a comparison was first made between the return period estimates obtained from a GPD (applied to Q99 events) and GEV (applied to AMAX). All years of data were used in the analysis; AMAX values were available for a range of durations for 223 stations, while Q99 events were extracted from 199 stations for 1-day maxima only. Regional Frequency Analysis (Hosking and Wallis, 1997) was applied first to 1-day maxima (1856-2009) for both series, and then $\sim 13 \sim$ 
only to 1-, 2-, 5- and 10-day AMAX to examine changes in frequency estimates over the period 1961-2009. While no specific measures of multiple day extreme rainfall were used in the development of the extreme regions, it is considered that the use of the newly developed Extreme Rainfall regions is more appropriate for this analysis than one based on the HadUKP regions estimated from mean rainfall characteristics. Furthermore, the magnitudes of longer accumulations are often influenced by a single day maxima, such that single and multiple day extreme characteristics are very similar.

Most examples in the literature of pooling POT maxima assume that all station maxima within a regional pool are of similar magnitude and so do not standardise the observation series. This is not appropriate for the regional pools under consideration, where considerable differences in elevation and aspect can exist between stations and so have an impact on the relative magnitude of station maxima. An adaptation of the Regional Frequency Analysis approach was adopted here, whereby the Q99 events were standardised by a station specific threshold equal to the 0.99 quantile and AMAX were standardised by the station specific RMED, prior to regional pooling. Lmoments were fitted to the individual station series for all stations in the region before deriving the regional L-moments from the weighted station average values and hence the distribution parameter estimates. The location parameter is known to be the threshold used to calculate the POT for each station; in this case a regionally weighted value of $\hat{u}$, calculated from all station thresholds, was adopted for the regionally fitted GPD. Testing confirmed that the regional RMED calculated from AMAX and that estimated from the regionally fitted GPD were similar, therefore the former RMED estimate was adopted for both GPD and GEV analyses for ease of comparison.

The calculated return period estimates for most regions, illustrated in Figure 6, follow a similar distributional shape and attain comparable magnitude estimates with both the GPD (applied to Q99 events) and GEV (applied to AMAX) models. However, it has previously been shown that for shorter time series, or small pools of data, return period estimates obtained from the GPD model are more robust to outliers (Davison and Smith, 1990), while with larger data sets there is little difference between the two methods. Five regions exhibit considerable differences in return period estimate magnitude between the GEV and GPD models: where NE, HUM, MW and EA have lower GPD growth curves than GEV; while the GPD growth curve for NHI is higher than the equivalent GEV growth curve. It is likely that these discrepancies have arisen from differences between the data sets, as AMAX for missing years were included when they could be verified from British Rainfall or other sources, while the equivalent missing years of POT data were omitted completely. The 
overlapping confidence intervals, estimated from the standard error estimates for each distribution parameter, for most regions also give greater credence to the similarity in the distributions. The confidence bounds for some GPD growth curves are so narrow that they are not visible in Figure 6; this may have arisen due to similarities in the regional maxima series and so reduced sampling errors in the parameter estimation.

Changes in return period estimates for each region over the period 1961-2009 were then examined, to evaluate the improvements in regional representation with respect to an equivalent analysis using the HadUKP regions (Jones et al., 2012; henceforth J2012). The analysis was applied to ten year rolling sub-sets (1961-1970, ..., 2001-2009) of the regional standardised 1-, 2-, 5- and 10day AMAX in a rolling decadal analysis. Seasonal maxima were not analysed, as variations in seasonal frequency and intensity require a more refined approach to account for the high degree of variability with respect to the time of year.

The benefit of the enhanced extreme regions is that trends which may have been ambiguous or statistically insignificant in previous assessments (Fowler and Kilsby, 2003; J2012) using the HadUKP regions are much clearer with this analysis and corroborate other spatial assessments of UK extreme daily rainfall (Perry, 2006; Jenkins et al., 2010). Furthermore, by representing geographical differences in extreme rainfall more effectively, a more robust analysis of regional behavioural changes is possible; the clearer trends estimated here are, therefore, not merely artefacts of the smaller regionalisation.

Figure 7 illustrates a selection of the rolling decadal analyses for different extreme regions and daily rainfall accumulations. For instance, $\mathbf{J} 2012$ reported a significant decrease in estimated return period magnitude in South East England between 1961-2010, a region encompassing the South East (SE), East Anglia (EA) and parts of the West Country (WC) and Humber (HUM) extreme rainfall regions. Using the refined regional definitions, the downward trend is more pronounced here for SE $\left(-0.3 \mathrm{~mm}\right.$ year $\left.^{-1}\right)$, while EA has no significant change. In contrast, northern and western regional short duration (1- and 2-day) maxima show significant increases of around $1 \mathrm{~mm}$ year $^{-1}$ over the whole period of the record from 1961-2010 (FOR, SOL, and SH), with insignificant changes in ES and NE, compared with $0.5 \mathrm{~mm}$ and $-0.05 \mathrm{~mm}$ year ${ }^{-1}$ for the East Scotland and North West England HadUKP regions respectively. Increases in the magnitude of longer duration (5-and 10-day) extreme rainfall, presumably arising from North Atlantic frontal systems, are also more apparent when using the new extreme rainfall region definitions, with significant upward trends approaching $2 \mathrm{~mm}$ year $^{-1}$ in regions with higher average elevation ( $\mathrm{NHI}, \mathrm{SH}$ ) than previously shown for the $\sim 15 \sim$ 
HadUKP South Scotland region. Using this method it is also possible to see which regions experienced particularly exceptional extreme rainfall in previous decades (ES, NI) or in more recent years (HUM, SOL, NE).

Figure 6 : Regional return period estimates generated from the regional Generalized Pareto distribution fitted to Peaks over the $99^{\text {th }}$ Quantile (red) and regional Generalized Extreme Value distribution fitted to AMAX (grey dashed) Figure 7 : Rolling decadal return period analyses for 1-day AMAX in (a) SE (b) EA (c) SOL; 2-day AMAX in (d) FOR, (e) HUM, (f) WC;

5-day AMAX in (g) NI, (h) NW, (i) NHI; and 10-day AMAX in (j) ES,(k) SH and (I) NE

\section{Discussion and Conclusions}

While regional frequency analysis of pooled extreme rainfall to estimate the likely impacts of a changing climate is a well established method, previous analyses have often used the Hadley UK precipitation regions (HadUKP; Alexander and Jones, 2000). Although, these regions have previously been found to be non-discordant for extreme rainfall (Fowler and Kilsby, 2003a), the regions were considered too spatially diverse to represent sub-scale variations in extreme rainfall. Therefore, given the increased interest in potential changes in extreme rainfall arising as a result of a warming climate, an improved definition of the rainfall regions, specifically for extreme rainfall,was considered necessary.

The HadUKP regions were originally developed from the mean rainfall characteristics of 27 stations in England and Wales (Wigley et al., 1984), and expanded later to Scotland and Northern Ireland using similar mean rainfall characteristics (Gregory et al., 1991). However, the behaviour of extreme rainfall differs considerably from that of the mean characteristics, with some considerable geographical differences in the frequency, timing and magnitude of events. Orography has a lesser influence over mean rainfall characteristics than over characteristics exceeding the variance in the distribution, that is on the rainfall maxima. By using extreme rainfall characteristics to characterize the regions, the geographical differences in behaviour are now better represented and so more robust analyses of changes in regional behaviour are possible.

Extreme daily rainfall characteristics such as magnitude, timing of events and variance in maxima were selected to describe the spatial differences in extreme daily rainfall. These parameters were then extracted from 199 stations to develop 14 regions, representing the temporal, orographic and atmospheric drivers affecting UK extreme rainfall. A paucity of records in upland areas such as the North Highlands and Islands or Mid Wales dictated that the regional boundaries are pragmatic at present, although these could be further enhanced through the use of additional data. 
Efficacy of the regions was first tested by comparing the return period estimates obtained from two extreme value distributions. A Generalized Pareto fitted to POT maxima and a Generalized Extreme Value distribution fitted to AMAX were largely comparable, although sensitive to the number of records included in the regional pool. The regional classifications were used as a spatial tool to examine variations in daily rainfall maxima over the last 50 years, and to establish improved estimates of event frequency. The results of the decadal trends confirm those found by others, with increases in long duration rainfall over recent decades in the north and west, and comparable decreases in shorter duration extremes in the South. The benefit of the new regional definitions is that results better reflect the climatology of extreme UK precipitation and avoid obscuring some extremes by averaging over larger regions. Analyses of changes in the annual maxima were also more informative, with the statistically significant trends being more clearly represented and reflecting those observed by other (Jenkins et al., 2010), through the use of more representative geographical behaviour.

Seasonal changes were not explored in this paper, as a more sensitive approach based on the observed peak frequency is required. This research was also suggestive of different atmospheric influences with respect to location, which were not examined in depth. The authors intend to enhance this research by studying both of these aspects in greater detail in the near future.

\section{Acknowledgements}

All analyses were carried out in R (R Development Core Team, 2011), using the following packages: nsRFA (Viglione, 2011), fields (Furrer et al., 2012), moments (Komsta and Novomestky, 2011), Imomco (Asquith, 2009), cluster (Maechler et al., 2011), and extRemes (Gilleland et al., 2009). This work was also supported by a NERC post-doctoral Fellowship award to Dr H. Fowler (2006-2010) NE/D009588/1. This work was part of a NERC funded Postgraduate Research Studentship NE/G523498/1 (2008-2012).

\section{References}

Alexander, L. V. and Jones, P. D. (2000) 'Updated precipitation series for the U.K. and discussion of recent extremes', Atmospheric Science Letters, 1, (2), pp. 142-150.

Alexander, L. V., Zhang, X., Peterson, T. C., Caesar, J., Gleason, B., Klein Tank, A. M. G., Haylock, M., Collins, D., Trewin, B., Rahimzadeh, F., Tagipour, A., Rupa Kumar, K., Revadekar, J., Griffiths, G., Vincent, L., Stephenson, D. B., Burn, J., Aguilar, E., Brunet, M., Taylor, M., New, M., Zhai, P., Rusticucci, M. and Vazquez-Aguirre, J. L. (2006) 'Global observed changes in daily climate extremes of temperature and precipitation', J. Geophys. Res., 111, (D5), pp. D05109.

Asquith, W. H. (2009) Imomco: L-moments, Trimmed L-moments, L-comments, and Many Distributions 
Blenkinsop, S. and Fowler, H. J. (2007) 'Changes in drought frequency and severity over the British Isles projected by the PRUDENCE regional climate models', Journal of Hydrology, 342, 50-71.

Blenkinsop, S., Fowler, H. J., Dubus, I. G., Nolan, B. T. and Hollis, J. M. (2008) 'Developing climatic scenarios for pesticide fate modelling in Europe', Environmental Pollution, 154, (2), pp. 219-231.

Bonell, M. and Sumner, G. (1992) 'Autumn and winter daily precipitation areas in Wales, 1982-1983 to 1986-1987', International Journal of Climatology, 12, (1), pp. 77-102.

Coelho, C. A. S., Ferro, C. A. T., Stephenson, D. B. and Steinskog, D. J. (2008) 'Methods for Exploring Spatial and Temporal Variability of Extreme Events in Climate Data', Journal of Climate, 21, (10), pp. 2072-2092.

Coles, S. (2001) An Introduction to Statistical Modeling of Extreme Values. Springer-Verlag,Berlin. Cooley, D., Nychka, D. and Naveau, P. (2007) 'Bayesian Spatial Modeling of Extreme Precipitation Return Levels', Journal of the American Statistical Association, 102, (479), pp. 824-840.

Corte-Real, J., Qian, B. and Xu, H. (1998) 'Regional climate change in Portugal: precipitation variability associated with large-scale atmospheric circulation', International Journal of Climatology, 18, (6), pp. 619-635.

Cunnane, C. (1988) 'Methods and merits of regional flood frequency analysis', Journal of Hydrology, 100, (1-3), pp. 269-290.

Dales, M. Y. and Reed, D. W. (1989) Regional flood and storm hazard assessment. in I. o. Hydrology(ed), Wallingford, Oxfordshire, OX10 8BB. Institute of Hydrology

Davison, A. C. and Smith, R. L. (1990) 'Models for Exceedances over High Thresholds', Journal of the Royal Statistical Society. Series B (Methodological), 52, (3), pp. 393-442.

Dommenget, D. and Latif, M. (2002) 'A Cautionary Note on the Interpretation of EOFs', Journal of Climate, 15, (2), pp. 216-225.

Ekström, M., Fowler, H. J., Kilsby, C. G. and Jones, P. D. (2005) 'New estimates of future changes in extreme rainfall across the UK using regional climate model integrations. 2. Future estimates and use in impact studies', Journal of Hydrology, 300, pp. 234-251.

Faulkner, D. S. (1999) Rainfall frequency estimation. Wallingford, Oxfordshire, OX10 8BB, UK.

Ferro, C. A. T. and Segers, J. (2003) 'Inference for clusters of extreme values', Journal of the Royal Statistical Society: Series B (Statistical Methodology), 65, (2), pp. 545-556.

Fowler, H. J. and Ekström, M. (2009) 'Multi-model ensemble estimates of climate change impacts on UK seasonal precipitation extremes', International Journal of Climatology, 29, 385-416.

Fowler, H. J. and Kilsby, C. G. (2003a) 'A regional frequency analysis of United Kingdom extreme rainfall from 1961 to 2000', International Journal of Climatology, 23, (11), pp. 1313-1334.

Fowler, H. J. and Kilsby, C. G. (2003b) 'Implications of changes in seasonal and annual extreme rainfall', Geophysical Research Letters, 30, (13), pp. 1720, doi:10.1029/2003GL017327.

Fowler, H. J., Cooley, D., Sain, S. R. and Thurston, M. (2010) 'Detecting change in UK extreme precipitation using results from the climateprediction.net BBC climate change experiment', Extremes, 13, pp. 241-267.

Fowler, H. J. and Wilby, R. L. (2010) 'Detecting changes in seasonal precipitation extremes using regional climate model projections: Implications for managing fluvial flood risk', Water Resour. Res., 46, (3), pp. W03525.

Furrer, R., Nychka, D. and Sain, S. (2012) fields: Tools for spatial data (6.6.3)

Gilleland, E., Katz, R. W. and Young, G. (2009) extRemes: Extreme value toolkit (1.60) [R package]. Gregory, S. (1975) 'On the delimitation of regional patterns of recent climatic fluctuations', Weather, 30, (9), pp. 276-287.

Gregory, J. M., Jones, P. D. and Wigley, T. M. L. (1991). Precipitation in Britain: an analysis of areaaverage data updated to 1989. Int. J. Climatol., 11, 331-345.

Hartigan, J. A. and Wong, M. A. (1979) 'Algorithm AS 136: A K-Means Clustering Algorithm', Journal of the Royal Statistical Society. Series C (Applied Statistics), 28, (1), pp. 100-108.

$$
\sim 18 \sim
$$


Hosking, J. R. M. (1990) 'L-Moments: Analysis and Estimation of Distributions Using Linear Combinations of Order Statistics', Journal of the Royal Statistical Society. Series B (Methodological), 52, (1), pp. 105-124.

Hosking, J. R. M. and Wallis, J. R. (1988) 'The Effect of Intersite Dependence on Regional Flood Frequency Analysis', Water Resources Research, 24, (4), pp. 588-600.

Hosking, J. R. M. and Wallis, J. R. (1993) 'Some statistics useful in regional frequency analysis', Water Resour. Res., 29, (2), pp. 271-281.

Hosking, J. R. M. and Wallis, J. R. (1997) Regional frequency analysis: an approach based on Lmoments. Cambridge University Press,Cambridge, UK.

Hossell, J. E., Riding, A. E. and Brown, I. (2003) 'The creation and characterisation of a bioclimatic classification for Britain and Ireland', Journal for Nature Conservation, 11, (1), pp. 5-13. Institute of Hydrology. (1975) Flood Studies Report. Natural Environment Research Council. IPCC. (2011) 'Summary for Policy Makers', in Special Report for Managing the Risks of Extreme Events and Disasters to Advance Climate Change Adaptation. Contribution of Working Group II. Intergovernmental Panel on Climate Change.

Jackson, M. C. and Larke, P. R. (1974) Frequencies of specified rainfall amounts within specified elevation over England and Wales. in Met Office(ed),

Jenkins, G., Perry, M. and Prior, J. (2010) The climate of the UK and recent trends. [Online]. Available at: http://ukclimateprojections.defra.gov.uk/content/view/816/500 (Accessed: 23/03/11). Jolliffe, I. T. (1972) 'Discarding Variables in a Principal Component Analysis. I: Artificial Data', Journal of the Royal Statistical Society. Series C (Applied Statistics), 21, (2), pp. 160-173.

Jolliffe, I. T. (1973) 'Discarding Variables in a Principal Component Analysis. II: Real Data', Journal of the Royal Statistical Society. Series C (Applied Statistics), 22, (1), pp. 21-31.

Jones, M. R., Fowler, H. J., Kilsby, C. G. and Blenkinsop, S. (2010) 'An updated regional frequency analysis of United Kingdom extreme rainfall 1961-2009', In: Proc. BHS 2010: Role of Hydrology in Managing Consequences of a Changing Global Environment. Newcastle, UK, 19-23 July 2010. BHS Third International Symposium, pp. 110-118.

Jones, M. R., Fowler, H. J., Kilsby, C. G. and Blenkinsop, S. (2012) 'An assessment of changes in seasonal and annual extreme rainfall in the UK between 1961 and 2009', International Journal of Climatology, early view DOI 10.1002/joc.3503

Jones, M. R., Blenkinsop, S., Fowler, H. J., Stephenson, D. B., Kilsby, C. G., (Submitted), 'Bimodal seasonality in regional extreme daily rainfall', Environmental Research Letters.

Jones, P. D. and Conway, D. (1997) 'Precipitation in the British Isles: An analysis of area-averaged data updated to 1995', International Journal of Climatology, 17, (4), pp. 427-438.

Kaiser, H. F. (1960) 'The application of electronic computers to factor analysis', Educational and Psychological Measurement, 20, pp. 141-151.

Katz, R. (2010) 'Statistics of extremes in climate change', Climatic Change, 100, (1), pp. 71-76.

Komsta, L. and Novomestky, F. (2011) moments: Moments, cumulants, skewness, kurtosis and related tests $(0.12)$

Lamb, H. H. (1972) British Isles Weather types and a register of daily sequence of circulation patterns, 1861-1971. pp. 85.

Macdonald, N., Jones, C. A., Davies, S. J. and Charnell-White, C. (2010) 'Historical weather accounts from Wales: an assessment of their potential for reconstructing climate', Weather, 65, (3), pp. 7281.

Maechler, M., Rousseeuw, P., Struyf, A., Hubert, M. and Hornik, K. (2011) cluster: Cluster Analysis Basics and Extensions (1.14.1)

Maraun, D., Osborn, T. J. and Gillett, N. P. (2008) 'United Kingdom daily precipitation intensity: improved early data, error estimates and an update from 2000 to 2006', International Journal of Climatology, 28, (6), pp. 833-842. 
Murphy, J., Sexton, D., Jenkins, G., Boorman, P., Booth, B., Brown, K., Clark, R., Collins, M., Harris, G. and Kendon, L. (2009) Climate change projections. July 2nd 2009 ed Met Office Hadley Centre,Exeter.

Neal, R. A. and Phillips, I. D. (2009) 'Summer daily precipitation variability over the East Anglian region of Great Britain', International Journal of Climatology, 29, (11), pp. 1661-1679.

Perry, M. (2006) A spatial analysis of trends in the UK climate since 1914 using gridded datasets. in N. C. I. Centre(ed), Exeter, UK. Met Office

Phillips, I. D. and McGregor, G. R. (2002) 'The relationship between monthly and seasonal Southwest England rainfall anomalies and concurrent North Atlantic sea surface temperatures', International Journal of Climatology, 22, (2), pp. 197-217.

R Development Core Team. (2011) R: A Language and Environment for Statistical Computing

Raziei, T., Bordi, I., Pereira, L. S., Corte-Real, J. and Santos, J. A. (2011) 'Relationship between daily atmospheric circulation types and winter dry/wet spells in western Iran', International Journal of Climatology.

Ribatet, M., Sauquet, E., Grésillon, J.-M. and Ouarda, T. (2007) 'A regional Bayesian POT model for flood frequency analysis', Stochastic Environmental Research and Risk Assessment, 21, (4), pp. 327339.

Robson, A. J. (1999) Statistical procedures for flood frequency estimation. Wallingford, Oxfordshire, OX10 8BB, UK.

Rodda, H. J. E., Little, M. A., Wood, R. G., MacDougall, N. and McSharry, P. E. (2009) 'A digital archive of extreme rainfalls in the British Isles from 1866 to 1968 based on British Rainfall', Weather, 64, (3), pp. 71-75.

Stedinger, J. R., Vogel, R. M. and Foufoula-Georgiou, E. (1993) 'Frequency analysis of extreme events', in Handbook of Hydrology. McGraw-Hill Companies.

Viglione, A. (2011) Non-supervised Regional Frequency Analysis (0.7-2)

Viglione, A., Laio, F. and Claps, P. (2007) 'A comparison of homogeneity tests for regional frequency analysis', Water Resour. Res., 29, (6), pp. 1745-1752.

Villarini, G., Smith, J. A., Baeck, M. L., Vitolo, R., Stephenson, D. B. and Krajewski, W. F. (2011) 'On the frequency of heavy rainfall for the Midwest of the United States', Journal of Hydrology, 400, (12), pp. 103-120.

Wigley, T. M. L., Lough, J. M. and Jones, P. D. (1984) 'Spatial patterns of precipitation in England and Wales and a revised, homogenous England and Wales precipitation series', International Journal of Climatology, 4, (1), pp. 1-25.

Wilks, D. S. (2005) Statistical methods in the atmospheric sciences : an introduction. 2nd ed Oxford Academic. 


\section{Tables:}

Table 1 : Rainfall variables used in Principal Component Analysis for Extreme Regions

Table 2 : Loadings of each variable within the first four principal components and proportional contribution (in italic) to the variance. Bold type indicates most significant contributing variables.

Table 3 : Extreme rainfall regions tests for homogeneity using the Hosking and Wallis heterogeneity test based on L-moment coefficient of variance, Anderson-Darling bootstrap test and discordancy measure. Bold font indicates critical test values exceeded, italic font indicates near critical values. 
Variable Name

Description

Calculation

sigmatilde

Scale parameter

Shape parameter

Generalized Pareto Distribution (GPD) fitted to

ksi

sintheta

Angular seasonality $99^{\text {th }}$ Quantile of daily station rainfall maxima

costheta

Rotational statistics applied to $99^{\text {th }}$ Quantile of

thetabar

daily station rainfall maxima

rbar $_{\text {se }}$

Mean value

g1

Seasonality vector 


$\begin{array}{cccc}\begin{array}{c}\text { Extreme } \\ \text { Region }\end{array} & \begin{array}{c}\text { Hosking and } \\ \text { Wallis Regional } \\ \text { Homogeneity }\end{array} & \begin{array}{c}\text { Anderson-Darling } \\ \text { Significance value }\end{array} & \begin{array}{c}\text { Number of } \\ \text { stations } \\ \text { approaching } \\ \text { critD }\end{array} \\ \text { NHI } & \mathbf{( \Theta )} & 0.98 & 1 \\ \text { ES } & -1.21 & 0.15 & 1 \\ \text { FOR } & 1.94 & 0.98 & 2 \\ \text { SH } & -0.42 & 0.52 & 0 \\ \text { NW } & 6.47 & 0.89 & 1 \\ \text { NE } & -1.87 & 0.06 & 0 \\ \text { HUM } & -0.76 & 0.57 & 1 \\ \text { EA } & 1.23 & 0.51 & 0 \\ \text { SE } & 0.97 & 0.61 & 0 \\ \text { WC } & 1.00 & 0.86 & 0 \\ \text { MW } & 0.22 & 0.87 & 4 \\ \text { SOL } & 2.30 & 0.86 & 1 \\ \text { SW } & 0.27 & 0.71 & 0 \\ \text { NI } & -0.49 & 0.84 & 1\end{array}$

Table 3 : Extreme rainfall regions tests for homogeneity using the Hosking and Wallis heterogeneity test based on Lmoment coefficient of variance, Anderson-Darling bootstrap test and discordancy measure. Bold font indicates critical test values exceeded, italic font indicates near critical values. 
Page 25 of 31

International Journal of Climatology - For peer review only
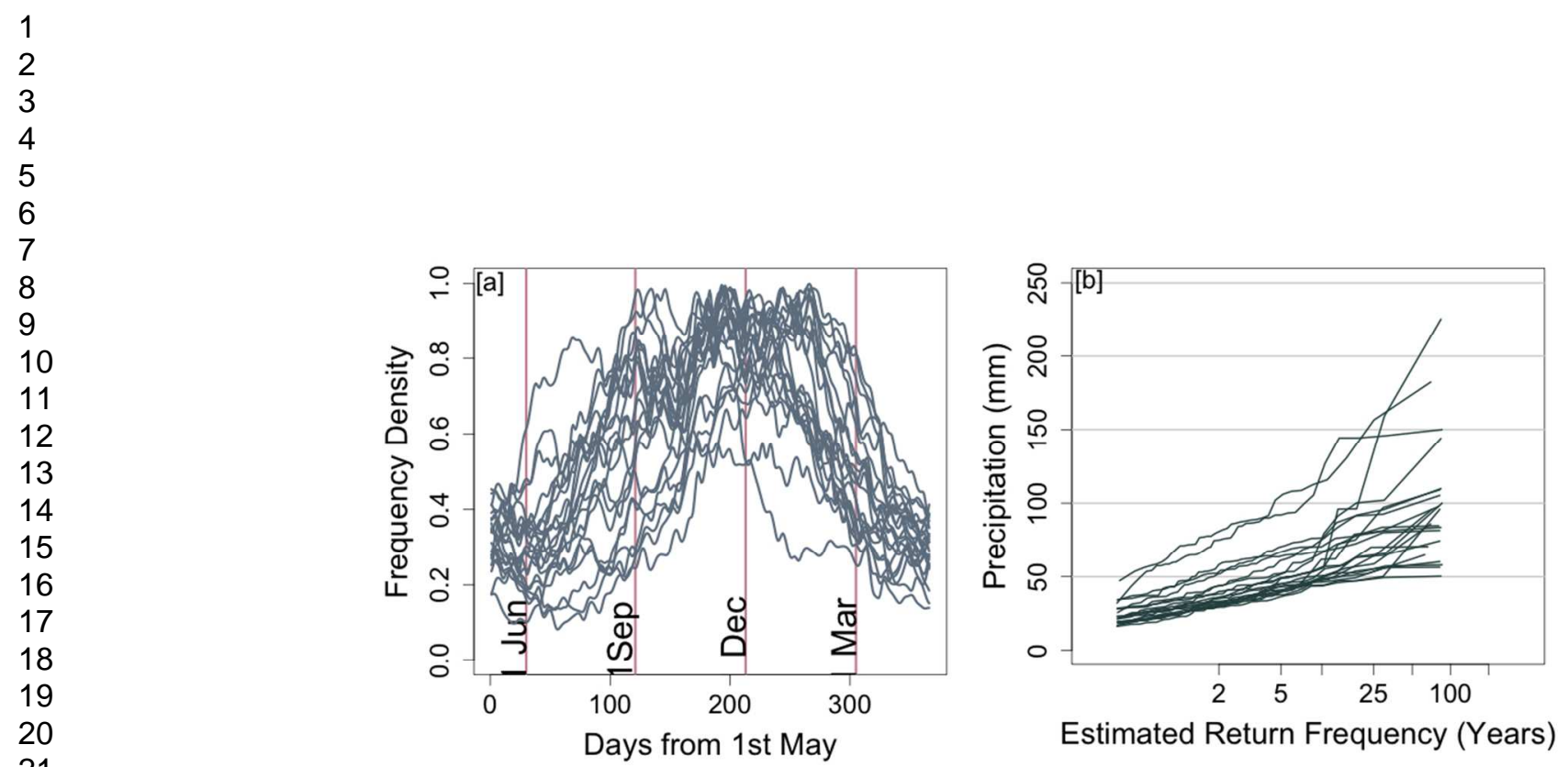

Figure 1 : Comparison of timing and magnitude of extreme rainfall at each station in the HadUKP North West England region $388 \times 176 \mathrm{~mm}(72 \times 72 \mathrm{DPI})$

http://mc.manuscriptcentral.com/joc 

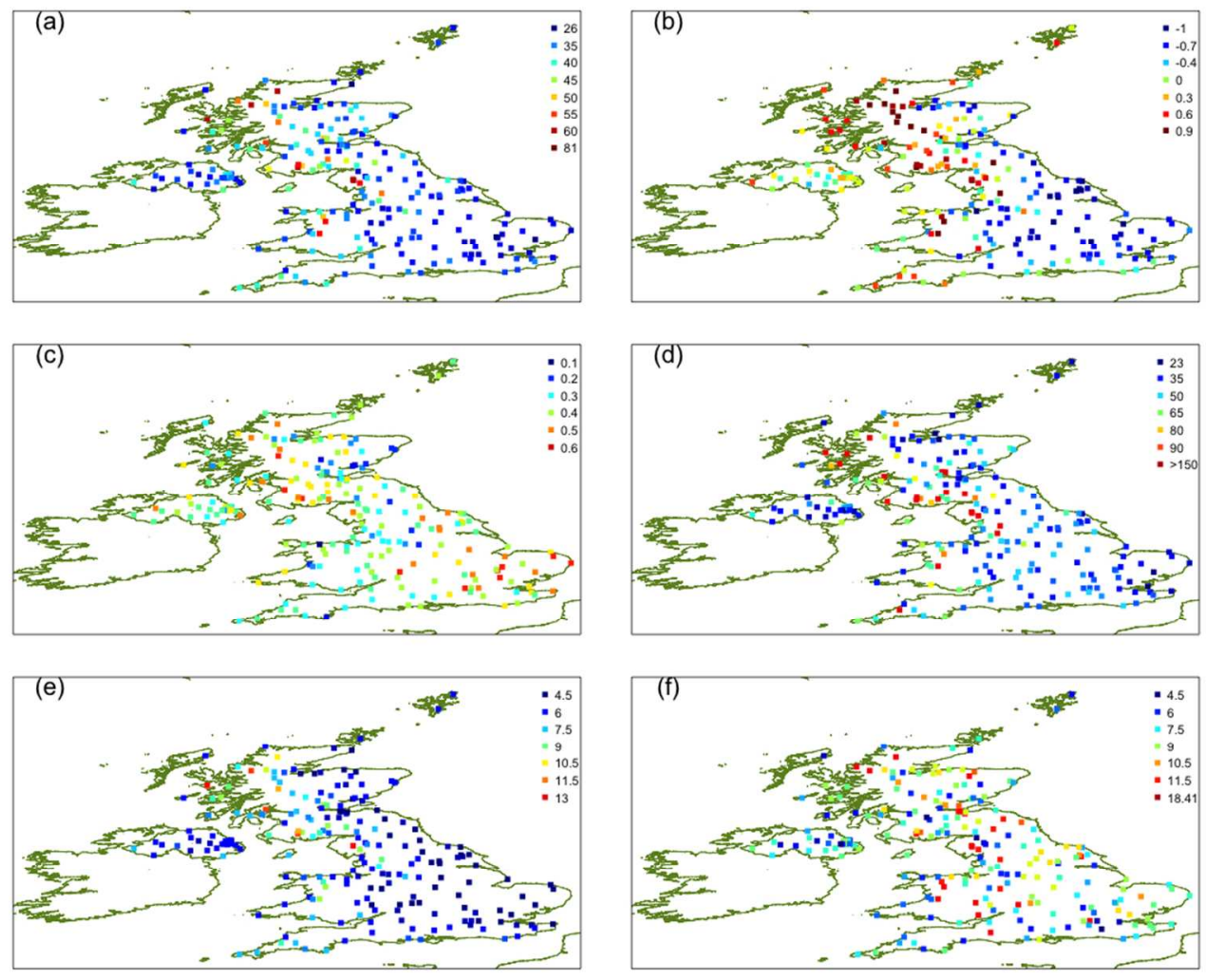

Figure 2 : Some measures of extreme rainfall used in a principal component analysis calculated for 19611990 period (a) RMED; (b) Rotational measure of day of event (c) Coherence of seasonality; (d) Count of summer days $>20 \mathrm{~mm}$; (e) Mean winter wet day value; (f) Fitted GPD scale parameter. $370 \times 299 \mathrm{~mm}(72 \times 72 \mathrm{DPI})$ 
a

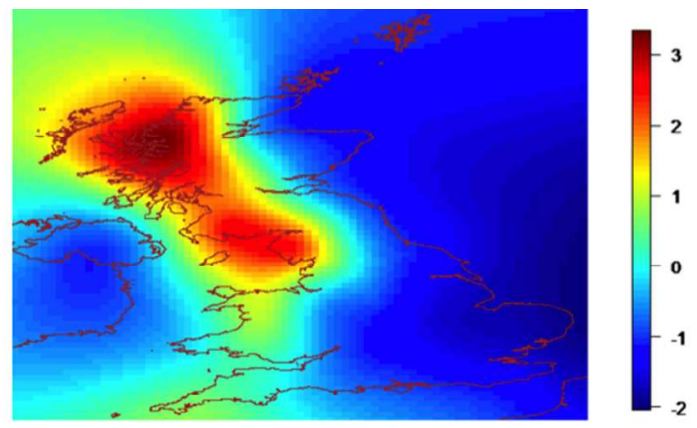

b

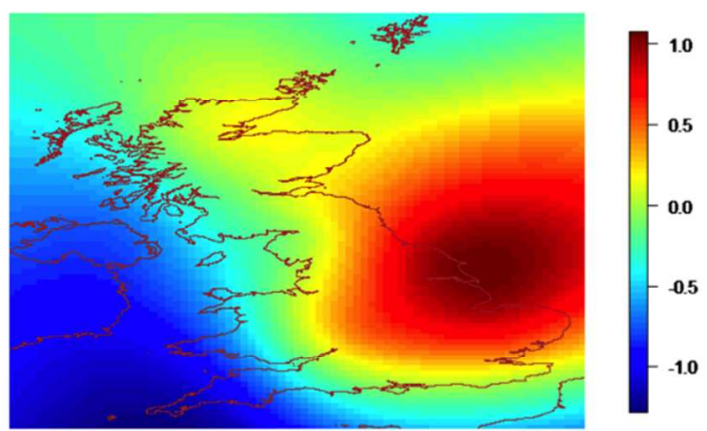

c

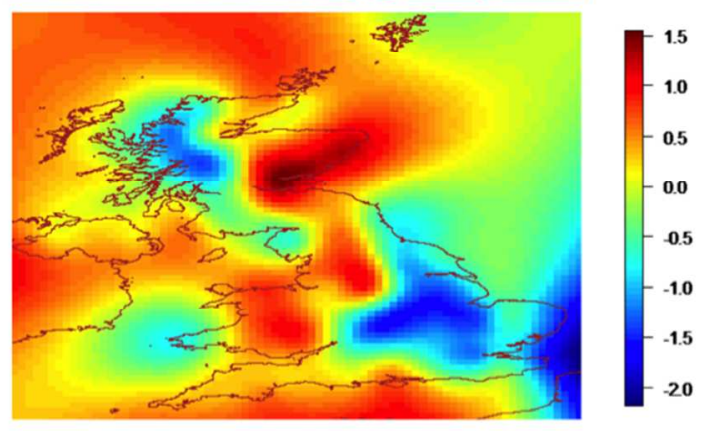

Figure 4 : Scores of principal components derived from the variables listed in Table 1 where (a) PC1 describes maxima; (b) PC2 describing variance in maxima; (c) PC3 describing seasonality 


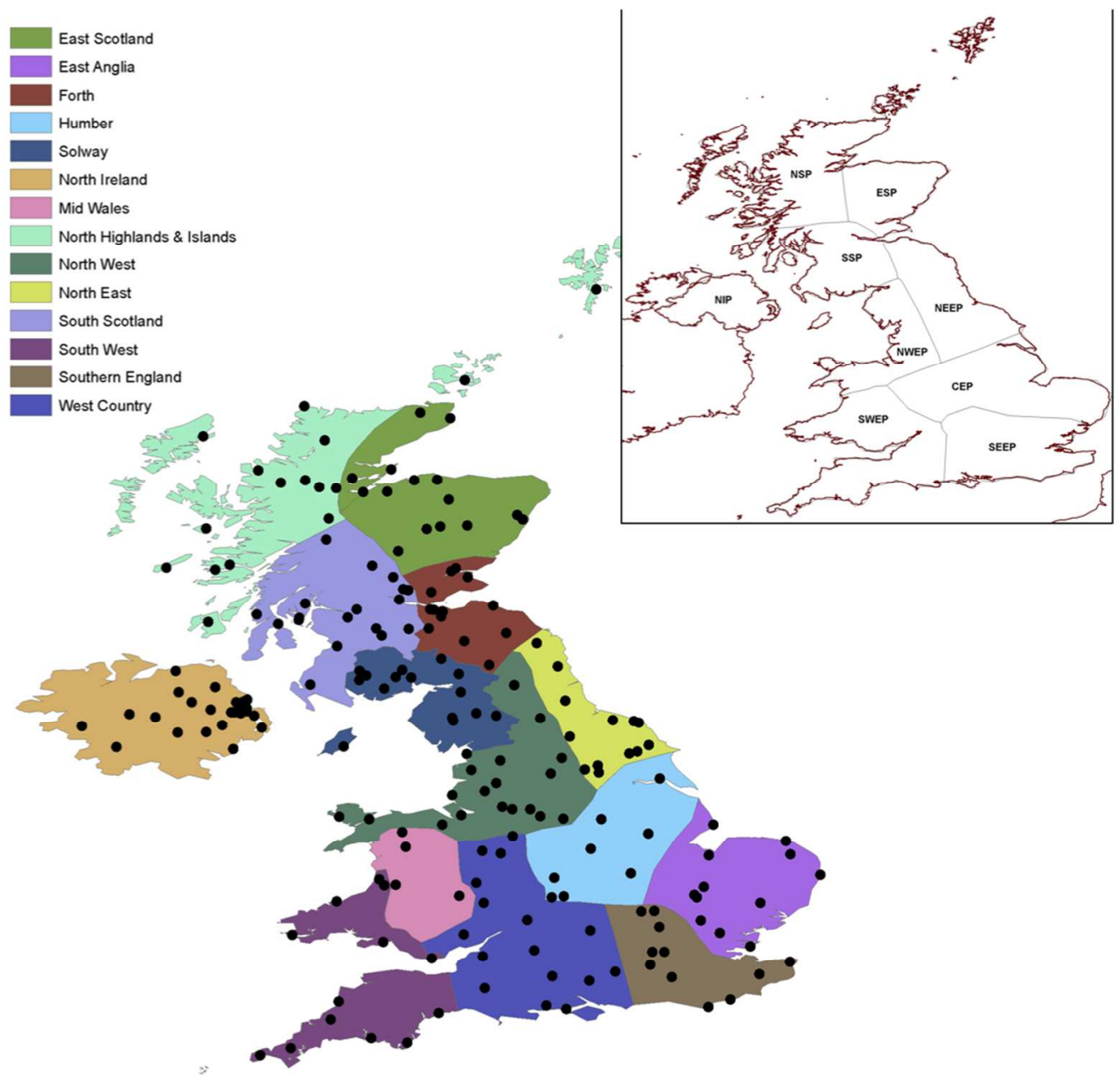

Figure 5 : UK Extreme Rainfall Regions identified from a principal component analysis of extreme rainfall measures. North Highlands and Islands (NHI), East Scotland (ES), South Scotland (SS), Forth (FOR), North Ireland (NI), Solway (SOL), North West (NW), North East (NE), Humber (HUM), Mid Wales (MW), East Anglia (EA), South West (SW), West Country (WC), South East (SE). HadUKP regions included in inset for reference. $193 \times 185 \mathrm{~mm}(150 \times 150 \mathrm{DPI})$ 

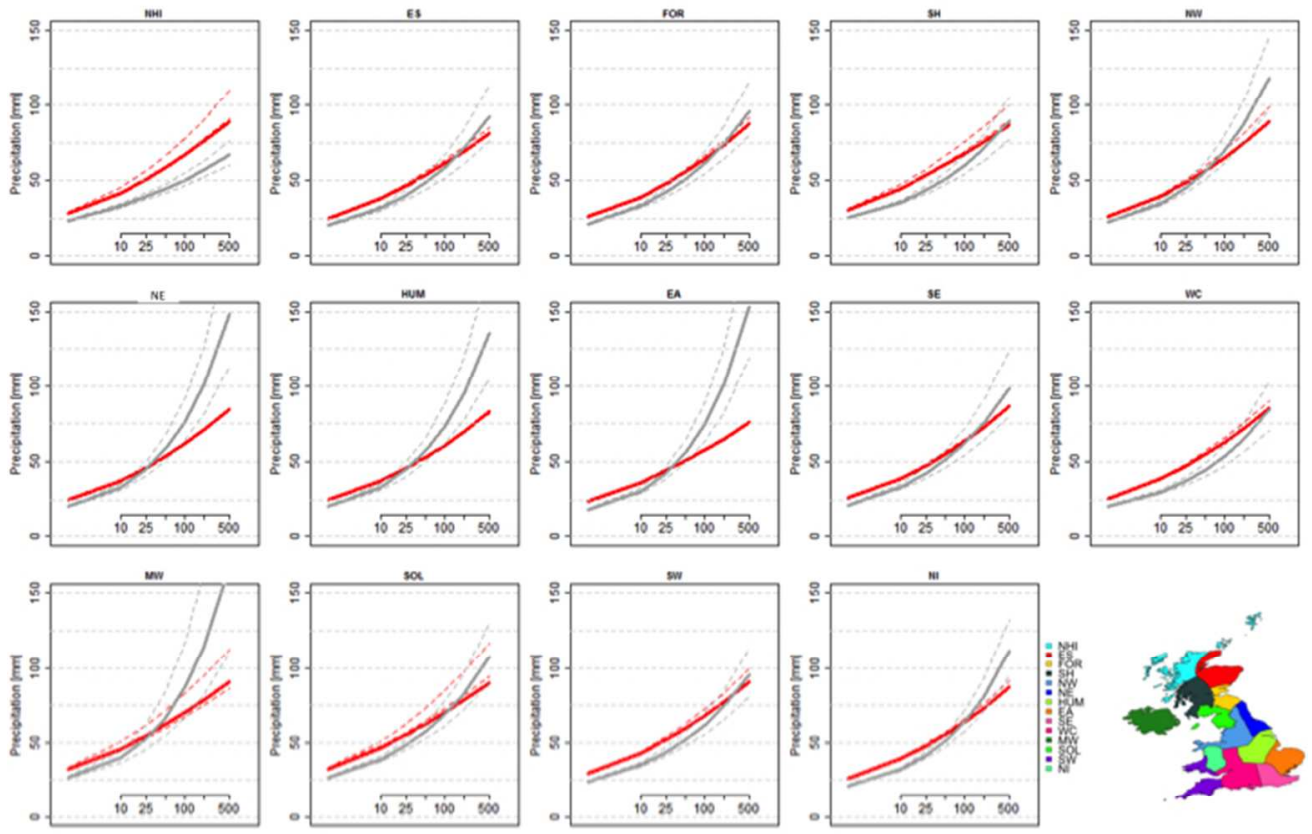

Figure 6 : Regional return period estimates generated from the regional Generalized Pareto distribution fitted to Peaks over the 99th Quantile (red) and regional Generalized Extreme Value distribution fitted to AMAX (grey dashed)

$254 \times 190 \mathrm{~mm}(72 \times 72$ DPI $)$ 
Figure 7 : Rolling decadal return period analyses for 1-day AMAX in (a) SE (b) EA (c) SOL; 2-day AMAX in (d) FOR, (e) HUM, (f) WC;

5-day AMAX in (g) NI, (h) NW, (i) NHI; and 10-day AMAX in (j) ES, (k) SH and (I) NE $352 \times 299 \mathrm{~mm}(72 \times 72 \mathrm{DPI})$ 